\title{
Effect of Temperature and Humidity on the Population Abundance of Spotted Oriental Cucumber Beetle Epilachna chrysomelina (F.) (Coccinellidae : Coleoptera) In Al - Qunfudah Western Saudi Arabia
}

\author{
SALEH A. AL-DIGAIL, AHMA I ASSAGAF and JAZEM A. MAHYOUB \\ Department of Biological Science, King Abdul-Aziz University, Jeddah (KSA).
}

(Received: May 18, 2012; Accepted: June 18, 2012)

\begin{abstract}
The Melon Ladybird Beetle, Epilachna chrysomelina (Coleoptera: Coccinellidae) Fabricius, is one of the major phytophagous insects that feed on cucurbit plants. E. chrysomelina which is considered an economic pest in agriculture is a multi-habitat insect widely distributed throughout the world .It is also endemic along the Southern and the Western coast of Saudi Arabia due to the abundance of cucurbit plants (wild and domesticated) where it passes through all four developmental stages. In this research it was found that temperature and humidity affect the insect biological activities through their effect on insect reproduction and development. During some parts of the year the insect is more abundant due to the favorable conditions of temperature and humidity for reproduction. The month of March was more favorable than February while January was the least favorable.
\end{abstract}

Key words: Epilachna chrysomelina (F.), The Melon Ladybird Beetle, Biological activities.

\section{INTRODUCTION}

The spotted oriental cucumber beetle $E$. chrysomelina ( $F$.) is a notorious pest feeding on many vegetable crops and attacks its most preferred plants specially members of the family Cucurbitaceae like pumpkin, sweet gourd, bitter gourd, cucumber, Cucumis mello, Cucurbita pepo and Citrullus lanatus ( Talhoq, 1982 ).

The pest damages in adult and larval stages during all vegetation of host plants. It damages mainly melons, cucumbers, pumpkins, and vegetable marrows. Watermelon is damaged in a lesser degree (Papointe and Shapiro, 1999 ; Lapointe, 2000).

The pest sometimes entirely consumes seedlings of the melons and gourds of late sowings, Beetles are more gluttonous during reproduction time (Al-Allan et al., 2008). Damaged melon and gourd fruits keep badly, decaying in 30-40 days (Shirai and Yara, 2001; Hiiesaar et al., 2005; Taylor and Schrader 2010 ) .

In Saudi Arabia, E. chrysomelina is one of the most injurious cucurbit attacking pests. The beetle is distributed throughout the country specially the South Western region( Abo-Thoria, 1982 ; Omaker et al., 2009).

The present work was planned to evaluate the effect of temperature and humidity on the population abundance of spotted oriental Cucumber beetle E. chrysomelina in Al- Qunfudah province Kingdom of Saudi Arabia.

\section{MATERIALS AND METHODS}

\section{Study area}

Al- Qunfudah province located on the west coast of the Kingdom of Saudi Arabia is one of 
the largest cities of Makka Al Mukarrama Region in Saudi Arabia, overlooking the Red Sea on the west, and away from the holy city of Mecca $350 \mathrm{~km}$ to the south, and away from Jeddah, $360 \mathrm{~km}$ (Fig. 1). Its geographic coordinates are 190742.18 " $\mathrm{N}$ and 41 05 11. 75" E level.

\section{Data collection}

The Cucurbit plant Momordia charantia was chosen to study the abundance of $E$. chrysomelina L. throughout the year. The plant grows naturally depending on the environmental conditions including soil moisture, however the beetles were observed congregating on this 4 preferred cucurbit plant feeding on its foliage, specially when there is no cucurbit plants growing in the vicinity The choice on M. charantia was based upon the following criteria :

1. The continued abundant availability of the host plant throughout the year.

2. The plant tolerates environmental fluctuations in (temperature, humidity and dryness of soil ).

3. The beetles thrive and nourish best on this plant throughout the year as considered it preferred host .

Method of calculating abundance of $E$. chrysomelina. The study started January 2009 up to December 2009 . Fifteen plants of Momordia charatia, having the same size were chosen. The plants were separated from each other at distances of approximately 15 meters, giving a total study area of 150 meter squared, and each plant was marked by given a serial number. The plants were visited monthly , recording number of insects present then, insects were collected by hand, during two periods, from 6. a.m. to 10. a.m. in the morning, and from 10. a.m. noon time. The monthly field visits took place during the middle of the month, and the temperature and $\mathrm{RH} \%$ were registered using a digital metrological instrument, and also temperature and $\mathrm{RH}$ data were obtained from the Metrology and Environment Protection Department.

\section{Data analysis}

Data were analyzed using SAS statistics software (version 6). Data were analyzed in order to find relationship \& correlation between climatic factors, and the population numbers of the cucurbit beetle E. chrysomelina Al- Qunfudah province.

\section{RESULTS}

The results showed a pronounced effect of the environmental factors as seen from the daily mean values of the temperature and R.H. on the daily emergence of the insect for feeding, and its behavioral activities. The level of activity was observed as related to the differences in insect numbers during certain periods of the year, hence the maximum numbers were recorded in March then February and April respectively with an average temperature of $22.72,21.95,25.21^{\circ} \mathrm{C}$ and R.H. of $64,66,64.5 \%$ respectively, which represents the optimum values for the beetles breeding and reproduction. The minimum population density of the insects was recorded during August, September and October where the average temperature and R.H. reached $31.39,29.02,27.28^{\circ} \mathrm{C}$ and $\mathrm{RH} 49$, $57,57.5 \%$ respectively (Table 1 ).

During the rest of the year the average population density fall between the average range. The E. chrysomelina beetles were affected by variation in the environmental conditions as regards to their activity and the different plant growth stages throughout the year. Moreover they thrive well in temperatures ranging between $23^{\circ} \mathrm{C}$ and $35^{\circ} \mathrm{C}$,

Table 1: Mean temp. and Humidity during the months of (Jan. - Dec. 2009)

\begin{tabular}{lcc}
\hline \multirow{2}{*}{ Month } & \multicolumn{2}{c}{ Mean } \\
\cline { 2 - 3 } & Temperature(C ${ }^{\circ}$ ) & Humidity(\%) \\
\hline January & 23.17 & 62.5 \\
February & 21.95 & 66 \\
March & 22.72 & 64 \\
April & 25.21 & 64.5 \\
May & 28.06 & 65.5 \\
June & 31.23 & 58 \\
July & 30.32 & 54.5 \\
August & 31.39 & 49 \\
September & 29.02 & 57 \\
October & 27.28 & 57.5 \\
November & 27.51 & 61 \\
December & 24.10 & 62 \\
\hline
\end{tabular}


and R.H. between 30 and $70 \%$. Out of these ranges there was pronounced reduction in growth and reproduction rate, and increase in mortality and inhibition in egg hatching.

Generally, E. chrysomelina beetles were abundant during January- May period, then their population numbers starts decreasing from June till October where it reached the minimum population numbers (Fig $2 \& 3$ ).

The beetle population was abundant during the morning period 6 a.m. to 10 am., and their numbers drop sharply from 10 to noon time with a complete absence of the beetles after 12 Oclock. The beetles were not 6 abundant after 10 a.m. during July to October due to the sharp rise in temperature after this time.

In the following analysis of results, correlations were used to explain the relationship between different climatic factors \& abundance of E. chrysomelina population in time \& space using data collected at 6AM-12AM and 6AM-12AM. Pearson's Correlation coefficient values suggest positive correlation and highly significant relationship between E. chrysomelina population and temperature, negative correlation significant relationship between E. chrysomelina population and relative humidity (Table. 2 ).

The analysis of variance (Table 2) indicated a highly significant difference $(p<0.01)$ between temperature and number of eggs, and a significant difference $(p<0.05)$ between R.H.\% and number of beetles at periods 6-10 a.m. and noon time.

This might give an indication that the feeding activities of the beetle E. chrysomelina on leaves of the host plants is affected by temperature and R.H. and the beetles were actively feeding early

Table 2: Pearson's correlation values between climatic factors and $E$. chrysomelina density

\begin{tabular}{lllll}
\hline \multirow{2}{*}{ Time } & \multicolumn{2}{c}{ 6AM-12AM } & \multicolumn{2}{c}{ 6AM-12AM } \\
\cline { 2 - 5 } Parameters & r-value & p-value & r-value & p-value \\
\hline Temperature & -0.76444 & $0.0038^{* *}$ & -0.76816 & $0.0035^{* *}$ \\
Relative Humidity & 0.63476 & $0.0266^{*}$ & 0.60005 & $0.0391^{*}$ \\
\hline $\begin{array}{l}{ }^{*} \text { Significant } \\
\text { ** } \text { high Significant }\end{array}$ & & & & \\
\end{tabular}
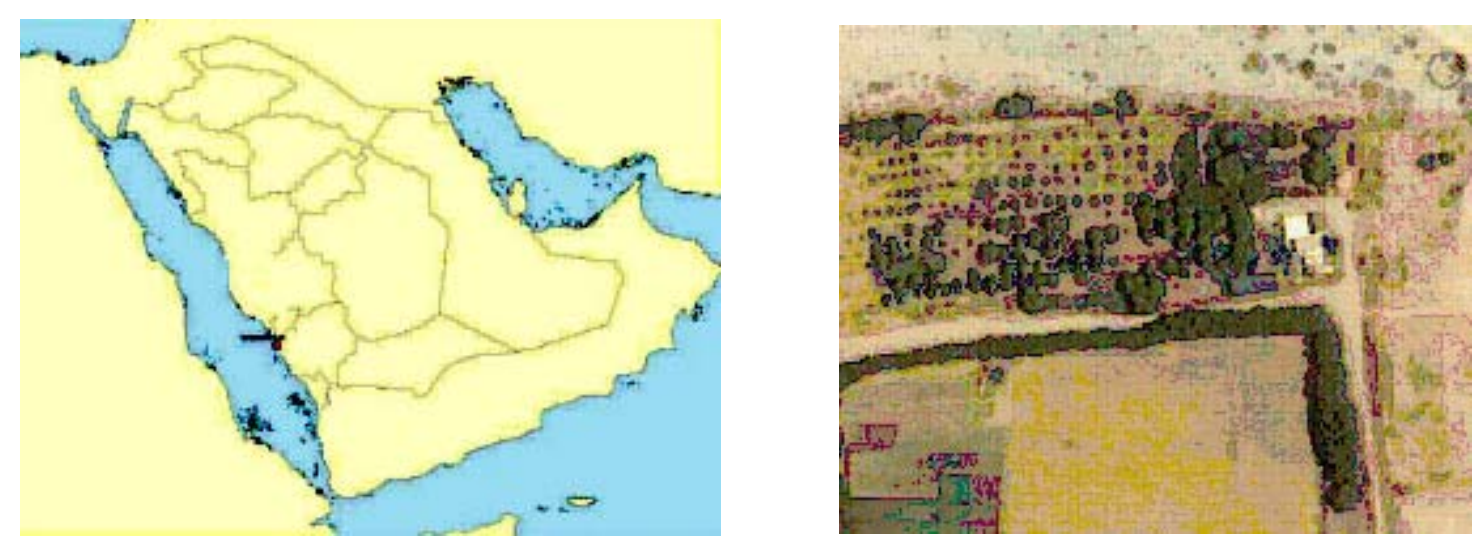

Fig. 1: Location of the study area in Al- Qunfudah City Kingdom of Saudi Arabia 
in the morning and their numbers decreased with increase in temperature and when R.H. starts decreasing . The beetles disappear completely after 12 oclock (Table 2), which illustrates the relationship between the beetle numbers on plants and temperature degrees and R.H. throughout the year .It is clear evident that the most suitable time for the beetles feeding lies between 6 to 10 a.m.

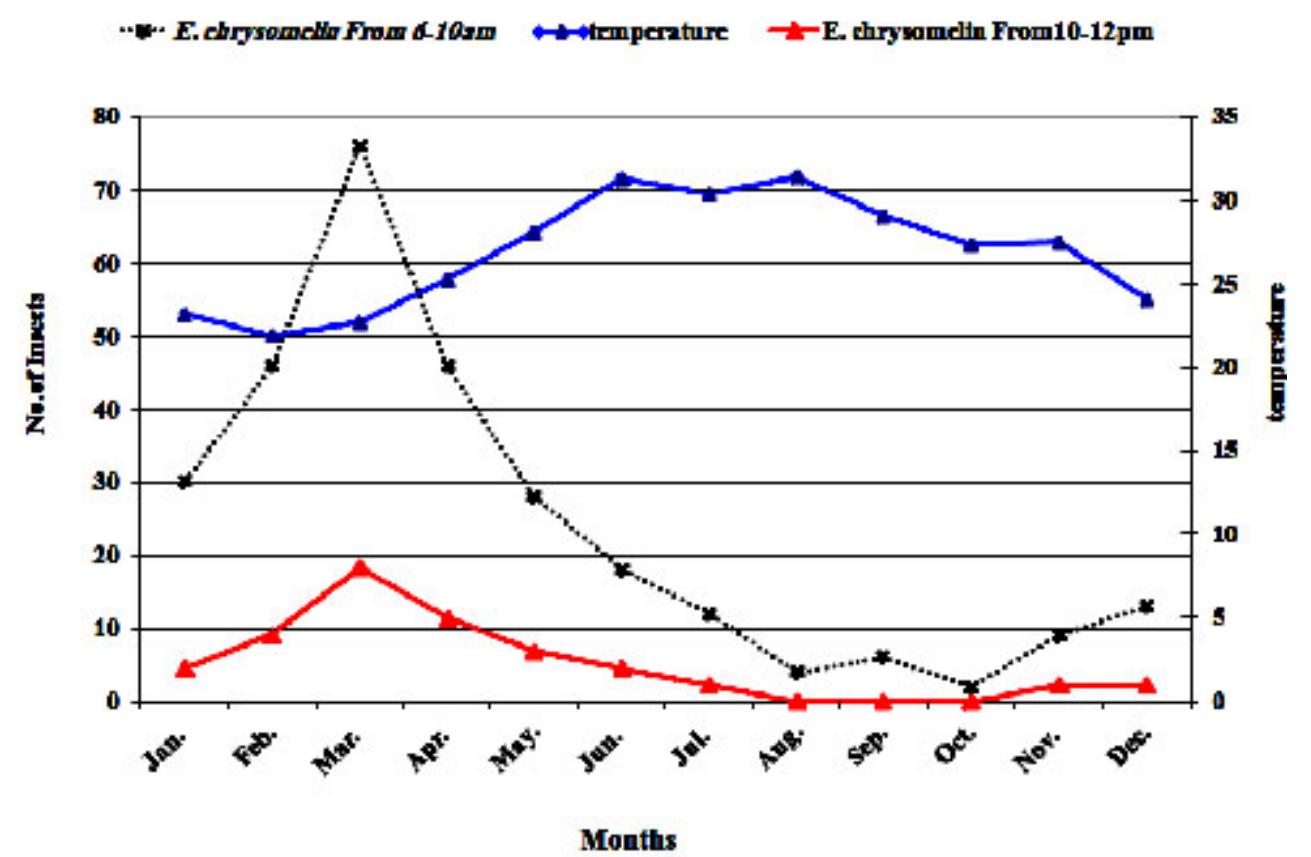

Fig. 2: The graph showing the relationship between abundance of E. chrysomelin \& temperature

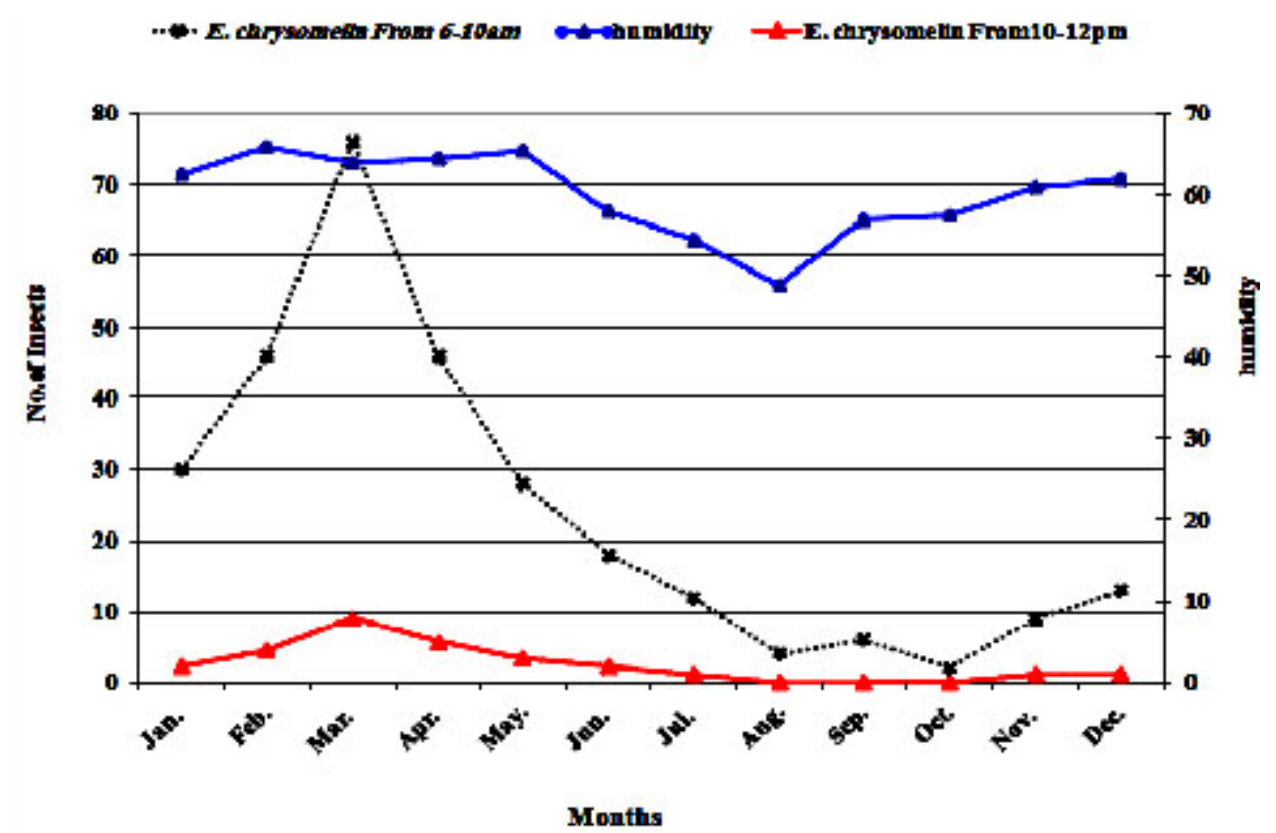

Fig. 3:The graph showing the relationship between abundance of $E$. chrysomelin \& humidity 8 
during March , April and February , and least present during October . Indicated ( Table 1 ) to averages of temperature and humidity during the year 2009.

\section{DISCUSSION}

It was clearly evident that E. chrysomelina is active during early morning hours and gradually disappears with rise in temperature as was mentioned earlier by Habeek et al., (1990) who reported marked effects of the environmental variations of the beetle population and our results were in agreement with these findings. Such effects are obvious from the influence of the daily mean temperature and R.H. on the presence of these beetles during their daily feeding in the field. The maximum number of the beetle present was during February, March and April, where the temperature and R.H. were at their optimum values $23^{\circ} \mathrm{C}$ and $70 \%$, and the minimum density was during August ,September and October with a rise of temperature to $36^{\circ} \mathrm{C}$ and the reduction of R.H. to $35 \%$. Abdelrahman ( 2005 ) mentioned that fixed temperature affects growth and reproduction of Coccinella undecimpunctata, suggesting that the optimum temperature for this carnivorous insect and its development ranges between 25 to $30^{\circ} \mathrm{C}$.

Taghizadah, ( 2008 ) reported that increasing temperature up to $40^{\circ} \mathrm{C}$ did not improve the insect development. There are significant differences between the rates of temperature decrease and the increase in the development and growth of the beetle, a fact which plays a vital role in the reproduction rate of the beetle and manifested in the increase in their numbers during certain periods of the year. The beetles appear feeding during day on different parts of the plant. In the early morning were observed on the upper surface of the leaf, and later when temperature starts rising hiding under the lower surfaces of the leaves, and at noon observed congregating below the plant between branches and on the soil near the bases of their host plant. It has been observed that the beetles prefer moist humid habitats in most agricultural fields, however the second best preferred host plant was bitter gourd in the absence of 11 cucumber, as an alternative host plant where they complete their life cycle..This plant emits volatile odors which probably attracted these beetles. Moreover E. chrysomelina beetles can differentiate between the different cucurbit plants because they were never observed feeding on , bitter melon plants .

Al-Allam , ( 2008 ) reported significant differences in egg hatching periods during temperature ranges between $28-30^{\circ} \mathrm{C}$, and no significant differences in the adult life span periods at temperature $32^{\circ} \mathrm{C}$. This might probably explain the reduction in beetle population density as a result of reproduction with increase in temperature.

The results indicated the absence of a significant correlation between egg numbers produced and R.H. , while the correlation is strongly significant with the number of eggs produced and temperature. These results are in agreement with some authors findings (Lapointe 2000; AbdelRahman 2005 ; Papointe and Shapiro 1999 ; Shirai and Yara 2001; Yunis et al., 2004).

\section{CONCLUSION}

In general, as evident from the results the activity of the pest is at its peak in the month of March; therefore it is recommended that the crop must be sprayed by insecticides during the month of January and February to control the activity of adult insects.

\section{ACKNOWLEDGMENTS}

The authors wish to extend their profound gratitude and appreciation to Sayed Mohammad Al Laithy for welcoming the conduction of this field study at his farm and thanks also goes to his 11 fellow workers who have contributed in the manual work near Al-Qunfotha town. Also deep thanks and appreciations were conveyed to the technical staff of the biological Science Department. Faculty of Science .King Abdul Aziz University for their appreciated efforts by giving a helping hand during data collection and the preparation of this manuscript. 


\section{REFERENCES}

1. Abdel-Rahman, M. ( 2005 ). Influence of constant temperature on the development , and reproductive potential of the ladybird beetle, Coccinella undecimpunctata L. ( Coleoptera : Coccinellidae). 3rd International Conf. on IPM role in Integrated Crop Management and Impacts on Envi. And Agr. Products, 26-29 (2005), Geiza ,Egypt.

2. Abo - Thoria, N. General account of agricultural pests in the King dom of Saudi Arabia .Agricultural Research and Water Management . Riyadh, Saudi Arabia , 268 (1982).

3. Al-Allan et al, Coccinella septempunctata L. (Coleoptera: Coccinellidae) Arab Scientist Organization, ArabScinetist.org. (2008).

4. Habeek, D. H. ,Bennett, F. D. andJ.H.Frank. Classical biological control in the southern United States. Southern Cooperative Serier Bull. No. 355 , IFAS Ed. ,Univ. Florida , Gainesville ,FL. 197 (1990).

5. Hiiesaar, K. ,Metspalu, L., Joudu, J. Jogar , K. ( 2005 ). Influence of low temperatures on development of preimaginals of Colorado potato beetles, Leptinotarsa decemlineata (Coleoptera : Chrysomelidae) 3rd International Conf. on IPM role in Integrated Crop Management and Impacts on Envi. And Agr. Products, 26-29 (2005), Geza ,Egypt.

6. Lapointe, S. L. (2000). Thermal requirements for development of Diaprepes abbrivatus (Coleoptera :Curculionidae). Environ.
Entomol. 29: 150-156 (2000).

7. Papointe, S. L. and J. P. Shapiro. Effect of soil moisture on development of Diaprepes abbrivatus ( Coleoptera: Curculionidae). Florida . Entomol. 82: 291-299 (1999).

8. Omakar C. ; S. Rastogi ; P. Pandey. Effect of temperature on reproductive attributes of the Mexican beetle Zygogramma bicolorata ( Coleoptera: Chrysomelidae ). Inter. Jour. of Tropical Insect Sci. 29: 48-52 (2009).

9. Shirai , Y. and Yara, K. Potential distribution area of the Mexican bean beetle, Epilachna varivestis (Coleoptera : Coccinellidae) in Japan, estimated from its high - temperature tolerance. Appl. Entomol. Zool. 36(4): 409417(2001).

10. Taghizaden, R., Y. Fathipour , and K. Kamali. Temperature-dependent development of Acarophagous ladybird, Stethorus gilvifrons ( Coleoptera: Coccinellidae). J. Asia-Pasific Entomol., 11(3): 145-148 (2008).

11. Talhoq, A.S. Applied Zoology in Saudi Arabia, Anote on the Entomophagous Insects. Fnuna and Saudi Arabia , 4: 525531 (1982).

12. Taylor, F. and R. Schrader ( 2010 ). Transient effects of photoperiod or reproduction in the Mexican bean beetle .Physio. Ento. 9(4): 459464 (2010).

13. Yunis, L. H. ; K. F. Azzawi ; A. F. Khalifa . Applied insect science. First Ed. ,Faculty of Agriculture , Iraq , 281- 290 (2004). 